\title{
Occupational overuse syndrome among keyboard users in Mauritius
}

\begin{abstract}
Ergonomics is a very important factor that cannot be over looked in the information technology working environment. This study was undertaken to assess reporting of occupational overuse syndrome (OOS) among keyboard users in Mauritius. A questionnaire-based survey was carried out among 362 computer users. Two hundred completed questionnaires were returned and data analyzed. The main findings from the present work showed symptoms such as eye problems and lower back, neck and shoulder pain were common among computer users. Severity of pain increased with number of hours of computer use at work. Reporting of OOS was higher among females. In conclusion, it is proposed that computer users need to be provided with an ergonomically conducive environment as well as to be educated and trained with respect to OOS. Implementation of such program(s) will go a long way towards preventing appearance of OOS symptoms among the young population currently engaged in the IT sector in Mauritius.

Key words: Computer, Environment, Mauritius, Musculoskeletal disorder, Occupational overuse, Pain, Repetitive stress injury, Syndrome
\end{abstract}

\section{INTRODUCTION}

Occupational overuse syndrome (OOS) is the name given to a range of conditions usually caused or aggravated by poor work processes and unsuitable working conditions. The OOS is also known as 'repetitive strain injury' (RSI), repetitive motion injury (RMI), carpal tunnel syndrome, or tenosynovitis. ${ }^{[1]}$ Such injuries may be induced by occupation, sports as well as leisure activities. ${ }^{[2]}$ Several actions that involve repetitive or forceful movements and the maintenance of constrained or awkward postures have been associated with such a musculoskeletal disorder. ${ }^{[2]}$ The condition is characterized by discomfort and persistent pain.

The characteristic symptoms of OOS often include swelling, numbness, restricted movement and weakness in or around muscles and tendons of the back, neck, shoulders, elbows, wrists, hands, or fingers. As such, for people experiencing symptoms of OOS, it may become difficult for them to hold objects or tools in their hands. These situations may thus affect the quality of life of the persons. ${ }^{[3]}$

The modernization in offices has led to the introduction of information technology (IT) tools in the work atmosphere. The acceptable trend in a normal working environment is consistent with the fact that more elements are becoming computerized and more people are using visual display terminals (VDT) and related equipment to complete their work. This situation is leading to an environment whereby many workers are exposed to potential problems associated with working with these equipment. ${ }^{[4]}$ The prevalence of overuse injury due to keyboarding tasks among keyboard users has been recognized worldwide. ${ }^{[5]}$ These tasks involve repetition of short movements within a short time.

In the literature, a myriad of factors have been identified to be associated with the development of OOS. ${ }^{[6]}$ The OOS can also be caused because of maintaining constrained postures for prolonged periods of time that contributes to restricted blood flow to the muscles. ${ }^{[1],[6]}$ Computer users adopt postures whereby the neck, shoulders and upper limbs remain in static positions for extended hours. . $^{[7],[8]}$ The more time spent on this type of activity, the higher the risk of developing such injuries. ${ }^{[9]}$ This fixed position also causes lower back pain due to the increased pressure on the vertebra while sitting. The sitting position, the type of chair, and use of footrest also affect the lower back. ${ }^{[8]}$ Although different management strategies have been developed to assist workers and supervisors to
A. H. Subratty, F. Korumtollee Department of Health Sciences, Faculty of Science, University of Mauritius, Reduit, Mauritius

For correspondence: A. H. Subratty, Department of Health Sciences, Faculty of Science, University of Mauritius, Reduit, Mauritius. E-mail: subratty@uom.ac.mu

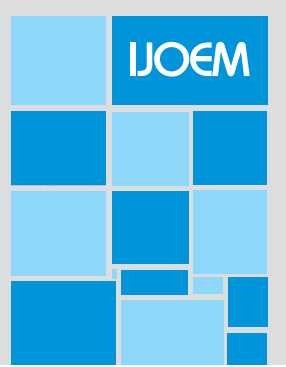


control such factors contributing to OOS, recent data indicate that the problem still persists. ${ }^{[9-11]}$ The review by Punnett and Bergvis ${ }^{[12]}$ concluded that the design of the workstation, long hours of computer use, and repetitive work such as keyboarding increased the risk of developing OOS symptoms. Studies have also shown that computer users are at greater risk of developing eye problems and visual fatigue. ${ }^{[9]}$ The position of the screen, especially the height and distance have been shown to cause eye strain and focusing difficulties.

As can be summarized, OOS is associated with a variety of occupations including telecommunication workers ${ }^{[5]}$ as well as newspaper workers. ${ }^{[6]}$ Symptoms have also been reported among Nigerian University staff whereby $82 \%$ of the respondents had symptoms suggestive of OOS. ${ }^{[9]}$

Mauritius has been making new developments in the IT sector. This is reflected in the emergence of call centers, software development companies, and the first cybercity. The number of computer users in Mauritius is therefore on the rise and this is expected to increase further in the coming years. There is currently no data pertaining to OOS in Mauritius. The main aim of this study is to evaluate the prevalence of OOS symptoms among keyboard users in Mauritius.

\section{MATERIALS AND METHODS}

\section{The questionnaire}

The research tool was an adapted prevalidated questionnaire along the theme based on a survey carried out at Central Queensland University. ${ }^{[13]}$ The questionnaire was divided into sections namely: clinical, computer use, workstation and work area, work environment, health indicators, and support. Data collected consisted of demographics such as age, sex, marital status and number of children. Other general information included weight, weight status, and job title. The questionnaire ends with a support section in which questions are asked about health and safety policies at work.

\section{Participants}

University employees, as well as public and private sector staff, who used computers during their working hours constituted the study population. Participants who use computer during their working hours and did not have any history of advanced muscular and bone disease were included into the study. Questionnaires were distributed and collected by the investigators. The participants were explained verbally and also provided with an information sheet about the rationale of the study, as well as the confidential nature of the information that was collected. Before entry into the study, participants had to sign a consent form.

A total of 326 questionnaires were distributed among computer users during the period August 2004-February 2005. Whenever there were delays in returning the questionnaires, a reminder was sent by e-mail or the respondent was contacted on the phone. At the end of data collection, completed questionnaires were reviewed before coding and entry for data analysis purposes.

\section{Statistical analysis}

The SPSS (Version 12.0.1 for Windows) package was used for the data analyses.

\section{RESULTS}

Out of the 326 questionnaires distributed, 200 (62\%) completed questionnaires were returned. Forty-one percent of participants were males, $58 \%$ were females, and $1 \%$ did not respond to this question. The age of participants ranged between 19 and 60 years. The participants all used a computer during their working hours and the job title included are shown in [Figure 1].

None of the participants had any previously diagnosed disease such as rheumatism, arthritis, or osteoporosis. Less than 7\% of participants suffered from diabetes, hypertension, and heart disease. However, $30 \%$ of participants mentioned that they had some muscular problems and $12 \%$ were on mild antiinflammatory drugs. Forty-one percent of participants reported using glasses, whereas use of contact lenses was prevalent among $13 \%$ of the study population.

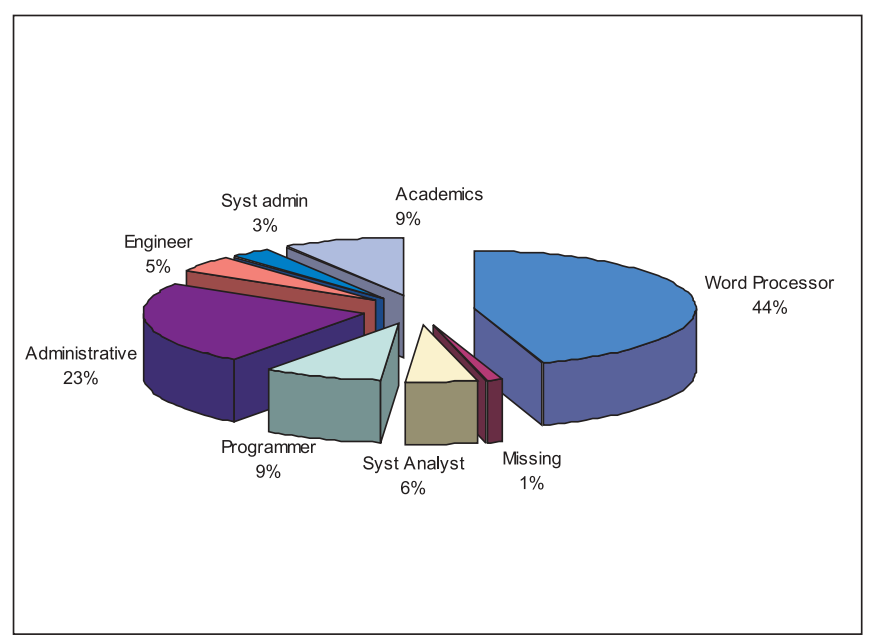

Figure 1: Job tittles of participants

Table 1: Number of years and hours of computer use

\begin{tabular}{cccc}
\hline No. of years & \% Participants & No. of hours/day & \% Participants \\
\hline$<5$ & 23.5 & $1-2$ & 7.0 \\
$5-10$ & 42.5 & $3-5$ & 27.6 \\
$11-15$ & 26.0 & $6-8$ & 43.2 \\
$>15$ & 8.0 & $>8$ & 21.6 \\
& & No response & 0.8 \\
\hline
\end{tabular}




\section{Computer use}

[Table 1] shows the number of years and number of hours of computer used by participants. There were low percentages of participants with more than 15 years of computer use and only $1-2 \mathrm{~h}$ of computer work per day.

\section{Typing skills}

About $73.5 \%$ of participants reported using all fingers, 20\% used two fingers for typing, and $6.5 \%$ reported using two fingers and typed slowly. However, it was not assessed whether they followed typing courses or have any certificates in typing.

\section{Work area and type of computer}

The most popular type of work area is the multi-person office (57\%) and $25 \%$ of participants work in individual office. The remaining used a combination of work areas including multiperson, individual office, and computer laboratories. The majority of participants (78\%) reported using the desktop as the main type of computer used, 3.5\% reported using a laptop and the remaining used a combination of both.

\section{Interruptions/breaks}

A large proportion (70\%) of participants reported frequent interruptions during their daily work. Fifty percent of participants took breaks for stretching. However, it was noted that respondents were not too keen to provide information about the duration of the break they took. Of those who did respond, it was reported that the interval between breaks varied between 25 and $240 \mathrm{~min}$. The great variation between breaks shows that it is possible that they took breaks after shorter lengths of time, but were not conscious of it.

\section{Work environment}

For $76.5 \%$ of respondents, their workload was manageable, whereas $17.5 \%$ of the study population found that it was too high. Four percent reported that their workload was relatively low. Pressure at work followed the same pattern as that of workload with $80 \%$ reporting a manageable level, $14 \%$ as too high, and $5 \%$ as too low. Most participants (85\%) felt that their work environment was friendly, whereas $11.5 \%$ thought that it was not, and 3.5\% did not respond.

\section{Workstation and work area}

[Table 2] summarizes the main findings for the part of the questionnaire dedicated to the participants' workstation, and the area that they work in. The chair and keyboard types and height adjustments, presence of footrest, mouse position, monitor characteristics, environment and phone use were investigated.

\section{Health indicators}

When respondents were asked to rate their general health, $10 \%$ thought it was excellent, $50.5 \%$ rated their health as good,
Table 2: Main findings on workstation and work area of participants in the study

\begin{tabular}{llll}
\hline $\begin{array}{l}\text { Workstation/ } \\
\text { work area }\end{array}$ & Characteristics & \multicolumn{2}{c}{$\%$ Respondents } \\
& & Yes & No \\
\hline Chair & Rolling chair & 90.0 & 8.0 \\
& Height adjusted & 81.0 & 18.0 \\
\multirow{2}{*}{ Keyboard } & Footrest present & 12.5 & 87.0 \\
& Keyboard height adjusted & 59.0 & 38.0 \\
Mouse & Type - conventional & 86.0 & 13.0 \\
Monitor & Beside keyboard & 85.5 & 14.0 \\
& Flat screen & 23.0 & 76.5 \\
& Monitor height adjusted & 61.0 & 38.0 \\
& Antiglare installed & 33.0 & 66.0 \\
& Tilt adjusted to minimize glare & 47.5 & 51.5 \\
& Monitor located so as to minimize & & \\
\multirow{2}{*}{ Climate } & contrast from the sun & 71.0 & 28.5 \\
& Adequate air circulation & 73.5 & 26.0 \\
Phone & Adequate space & 65.0 & 34.5 \\
& Frequently talking on phone & 51.0 & 48.5 \\
Other instruments & Frequent user of other instruments & $47.0^{* *}$ & 52.5 \\
\hline
\end{tabular}

** Most frequently used instrument is the mobile phone $44 \%$ of respondents.

Table 3: Symptoms and their frequencies (\% participants)

\begin{tabular}{lccc}
\hline Symptoms & Never & $\begin{array}{r}\text { \% Participants } \\
\text { Occasionally }\end{array}$ & Frequently \\
\hline Visual problems & 40.5 & 50.5 & 9 \\
Tingling in extremities & 55.5 & 37.5 & 6.5 \\
Emotional stress & 49.5 & 38.5 & 10.5 \\
Headache/migraine & 26.5 & 54 & 19 \\
Neck pain & 23.5 & 52 & 24 \\
Shoulder pain & 24 & 52 & 23.5 \\
Arm pain while using mouse & 64.5 & 26 & 9 \\
Arm pain & 56 & 34.5 & 9 \\
Wrist pain & 60 & 31.5 & 8 \\
Pain in fingers & 65 & 27.5 & 7 \\
Lower back pain & 25.5 & 50 & 23.5 \\
\hline
\end{tabular}

$36.5 \%$ thought it was satisfactory, and 2\% rated themselves as having a poor health. Participants were also specified pain locations and were asked to rate the frequency of their pain. [Table 3] shows the pain locations and their frequencies.

On an average, $54.5 \%$ of participants had some type of pain from the listed locations. The highest prevalence was neck pain (76\%), followed by shoulder pain (75.5\%) and lower back pain (73\%). Participants were also asked to specify the severity of pain at the different locations. Figure 2 shows the perceived severity of pain. Pains with highest severity were for headache, lower back neck and shoulder pain. Highest prevalence of moderate pain was for lower back, neck, shoulder, and migraine. Only 20\% were reported to miss work due to OOS symptoms, and a maximum of 2 days work loss was reported and they all sought medical assistance.

\section{Support}

Aspects of support at work were also investigated. The majority of respondents, $88 \%$, reported that their supervisor did not consider potential health effects and amount of time that would be required for tasks assigned. More than half of 


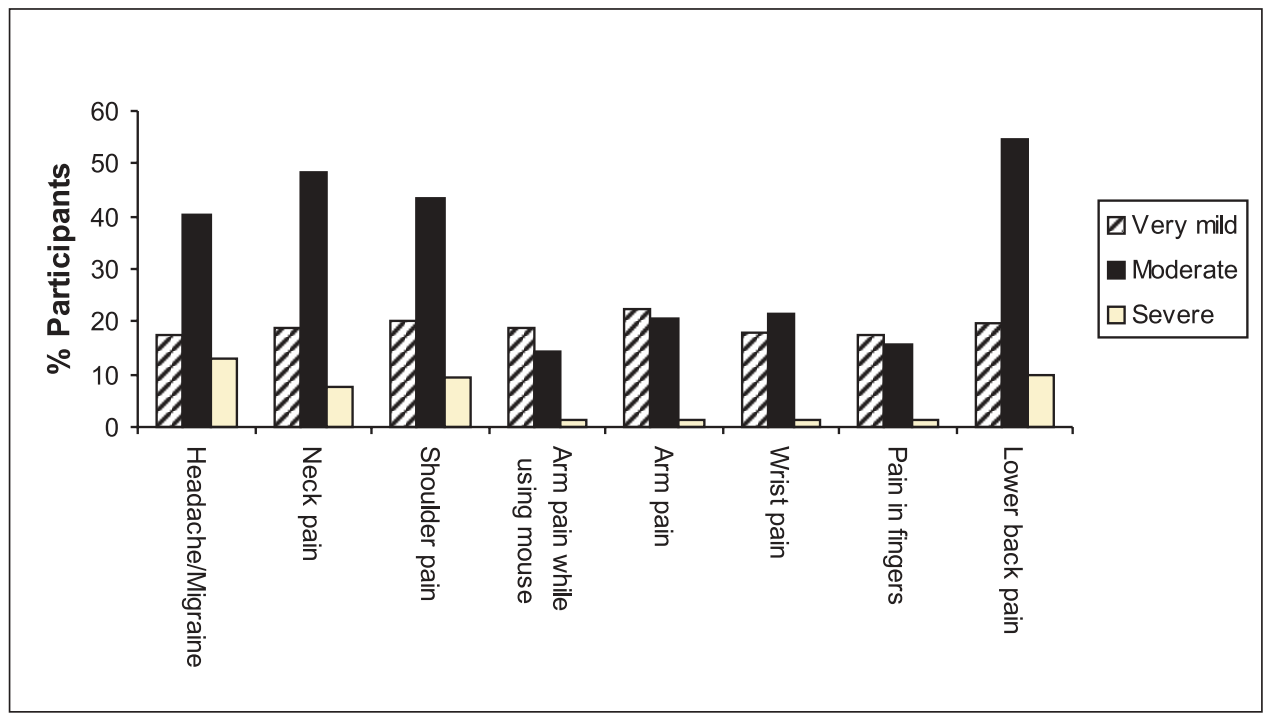

Figure 2: Perceived severity of pain

the respondents reported that they were trying to improve their work conditions. Some respondents, 34\%, were aware of health and safety policies about computer use in general. However, $79 \%$ reported that they did not have any such policies at their work place.

\section{DISCUSSION}

Occupational overuse syndrome, which is an ergonomic injury, is attracting much attention because this syndrome is becoming more frequent because decreased productivity and costs in worker compensation, and medical expenses are on the rise. Computer use is one of the numerous reasons for the increase in OOS.

The response rate (62\%) obtained from participants in this study correlates with other studies. ${ }^{[6-8]}$ The possible reasons for this response rate could be because of the possibility that nonrespondents are not willing to give personal information. It is also worth mentioning that the workforce in the IT sector in Mauritius is a relatively young population and have not yet started showing symptoms of OOS; thus this could be the reason for the lack of interest to fill and return the questionnaire. In the literature, it is evident that low rates of reporting could be due to the ignorance of significance of pain, strong work ethics, fear of losing job, economic pressure, absence of nonrepetitive duties, and attitudes of supervisor, health personnel and fellow workers. ${ }^{[2]}$

It was noted that $87 \%$ of respondents did not have a footrest and that $73 \%$ reported having lower back pain. This has also been reported in previous studies. The static sitting position for extended hours increases intradiscal pressure, disc degeneration, and poor disc nutrition may be related with the reported back pain. ${ }^{[8]}$
Previous studies have reported an association between VDT and eye problems. ${ }^{[14]}$ A prevalence of $59.5 \%$ visual problems was found among respondents in the present study. Monitor height and glaze angle also affect the eyes, lower monitor height are likely to reduce eye discomforts. ${ }^{[10]}$ In the present study, 66\% did not have antiglare screen installed and $>50 \%$ did not adjust monitor tilt to minimize glare. Such poor working conditions might be a possible explanation to the high rate of visual problems reported.

Neck and shoulder pain were among the most prevalent disorders, 76 and $75.5 \%$, respectively. Previous studies have shown that computer users are at increased risk of having such symptoms. ${ }^{[15]}$ Neck and shoulder pain could be caused by poor workstation position including sitting posture, monitor position and keyboard height. ${ }^{[15]}$ Monitor height and flexion of the head to avoid glare are possible factors for the reported headache, neck pain, shoulder pain, and eye discomfort. ${ }^{[10]}$ It is worth noting that in the present study, highest severity of pain was reported for neck and shoulder.

Tingling in the extremities was reported by more than $40 \%$ of respondents. This is an OOS symptom caused because of maintaining fixed positions for long hours. ${ }^{[7]}$

Studies have shown that short breaks have a protective effect over the development of OOS. ${ }^{[7],[11]}$ In this study, it was found that $50 \%$ of participants took breaks to stretch and the interval between breaks ranged from 25 min to as long as 240 min. However, a study has shown that breaks at 20-minute interval were beneficial, whereas microbreaks did not have any protective effect. ${ }^{[15]}$ It has been reported that many computer users are unaware of the importance of taking such breaks or do not have time to take breaks as they have to meet deadlines. ${ }^{[1]}$ It was also found that the majority, 69\%, of 
respondents were not aware of any health and safety policies on computer use in general, and a further $80 \%$ were not aware of any such policies at their current workplace. This shows the lack of information among computer users and therefore a need for prevention programs.

The main findings from the present study have highlighted eye problems, lower back pain, and severity of pain increased with number of hours of computer use as well as length of employment in the respective job. Report of symptoms of OOS was higher among female participants (58\%). This situation could be explained by the fact that word processing duties, clerical works, and secretarial jobs are female-dominated duties and not due to discrimination. ${ }^{[8]}$

Our findings are in agreement with those reported elsewhere in the literature. ${ }^{[7],[8]}$ In the United States and other Western industrialized countries, similar complaints involving visual problems and pain have been reported among computer users. ${ }^{[11],[14]}$

The OOS symptoms can vary from person to person and may often involve more than one part of the body. ${ }^{[2]}$ Pain generally stops with rest, but prolonged periods of rest may be necessary to reduce severe pain. ${ }^{[2]}$ If nothing is done to redesign the work area to eliminate or reduce the risk of injury, then permanent damage may result. The sufferer may have difficulties performing other activities such as reading and driving. ${ }^{[6]}$

If there is enough variation in the tasks, the body can recover from such stressful work. One has to take into account that the duration and the amount of time spent towards completing repetitive tasks over the working day are significant. So the concept of 'rest' time is an essential criterion that should not be overlooked. ${ }^{[1]}$

Our findings recommend the need to have modified worksite equipments that are essential to decrease awkward posture and poor body alignment. Such improvement in the working environment involve the need to provide comfortable seating options, wrist rests, foot rests, lowered keyboard heights and copyholders, thus ensuring good work habits.

\section{CONCLUSION}

Musculoskeletal disorder is one of the key health and safety issues of the modern IT era. There is need for implementation of programs that include the concepts of ergonomics, health education, training of personnel so as to be able to prevent and overcome the phenomenon of OOS.

\section{ACKNOWLEDGMENTS}

The authors are grateful to the University of Mauritius for providing financial support for this work.

\section{REFERENCES}

1. Bammer G. How technologic change can increase the risk of repetitive motion injuries. Seminars in Occup Med 1987;2:25-30.

2. Browne CD, Nolan BM, Faithfull DK. Occupational repetition strain injuries: Guidelines for diagnosis and management. Med J Aust 1984;140:329-32.

3. Taylor K. Research on RSI and Breaks. http://www.nichesoftware.com

4. Bholah R, Fagoonee I, Subratty AH. Sick Building Syndrome in Mauritius: are symptoms associated with the office environment? Indoor Built Environ 2000;9:44-51.

5. Pan CS, Schleifer LM. An exploratory study of the relationship between biomechanical factors and right-arm musculoskeletal discomfort and fatigue in a VDT data-entry task. App Ergon 1996;27:195200.

6. Jensen C, Ryholt CU, Burr H, Villadsen E, Christensen H. Work-related psychosocial, physical and individual factors associated with musculoskeletal ymptoms in computer users. Work \& Stress 2002;16:107-20.

7. Ortiz-Hernandez L, Tamez-Gonzalez S, Martinez-Alcantara S, MendezRamfrez I. Computer use increases the risk of musculoskeletal disorders among newspaper office workers. Arch Med Res 2003;34:33142.

8. Green RA, Briggs CA. Prevalence of overuse injury among keyboard operators; characteristics of the job, operator and the work environment. J Occup Health Safety Aust New-Zealand 1990;6:109-18.

9. Ijadunola KT, Ijadunola MY, Onayade AA.Perceptions of Occupational Hazards amongst Office Workers at the Obafemi Awolowo University, Ilfe-Ife. Niger J Med 2003;12:134-9.

10. Burgess-Limerick R, Plooy A, Fraser K, Ankrum DR. The influence of computer monitor height on head and neck posture. Int J Ind Ergon 1999;23:171-9.

11. Berghqvist U, Wolgast E, Nilsson B, Voss M. Musculoskeletal disorders among visual display terminal workers: individual, ergonomic, and work organizational factors. Ergonomics 1995;38:763-76.

12. Punnett L, Bergvist U. Visual display unit work and upper extremity musculoskeletal disorders. Stockholm: National Institute for Working Life 1997.

13. Zelmer AC. OOS and Computer use among NTEU members at CQU: Pilot Study report. Occupational overuse Syndrome (OOS) and computer use among NTEU members at Central Queensland University. Central Queensland University: 2000.

14. Berghqvist UO, Knave BG. Eye discomfort and work with visual display terminals. Scand J Work Environ Health 1994;20:27-33.

15. Wahlström J, Hagberg M, Toomingas A, Tornqvist WE. Perceived muscular tension, job strain, physical exposure, and associations with neck pain among VDU users; a prospective cohort study. Occup Environ Med 2004;61:523-8

16. McLean L, Tingley M, Scott RN, Rickards J. Computer terminal work and the benefit of microbreaks. App Ergon 2001;32:225-37. 